\title{
APPENDIX C: DESCRIPTIONS - PRE-SELECTED SUSTAINABLE DEVELOPMENT INDICATORS (SDIS) FOR THE SURFACE MINING PROCESS ${ }^{\text {is }}$
}

\section{C.1. PROJECT AND ENVIRONMENTAL MANAGEMENT EXCELLENCE - PEME}

Biophysical Impact Assessment (BoiIA) assesses the baseline conditions of a determined environment and evaluates the biophysical impacts of a project on a particular region.

Cumulative Environmental Impact Assessment (as per cumulative impact threshold requirements for Alberta oil sands) evaluates the changes to the environment caused by an action in combination with other past, present and future human actions, regardless of who undertakes such actions.

Economic Impact Assessment (EcIA) appraises the effects, both positive and negative, on the economy of a determined policy, programme, activity, project or event.

Emergency Response Management Plan describes the measures, procedures and processes that should take place in the event of an emergency in the project. 'Emergency' refers to any situation or impending situation that constitutes danger that could result in harm to persons or substantial damage to property or the environment.

Environmental Impact Assessment (EIA) refers to possible impacts and effects - either positive or negative - that a proposed development or project may have on the environment.

Environmental Management Systems (EMS) are systems commonly supported by a database in which a set of management procedures and processes are

\footnotetext{
This appendix is courtesy of WIT Press from Poveda and Lipsett (2014, pp. 73-86). Portions of the content in this appendix have been adapted and updated accordingly.
} 
documented, allowing an organisation to identify, evaluate and reduce the environmental impact of its activities. The set of documents are used for training personnel, monitoring and reporting environmental performance to internal and external stakeholders of the organisation.

Environmental Protection Management Plan outlines the environmental management approach and protection measures that will be considered in each phase of the project's life cycle. The plan describes the measures to be applied throughout the project, while highlighting the measures to be considered in specific construction phases and project components.

Environmental Risk Management Plan is a set of actions and measures to be undertaken to reduce potential risks arising from any activity performed during the project life cycle. Actions and measures are meant to focus on protecting the environment and reducing the diverse impact due to project development.

Erosion and Sediment Control Plan describes the appropriate actions and practices for protecting the ecosystem from erosion and sedimentation occurring as a result of mining activities.

Hazard Management Plan (which includes assessments, inspections, and procedures) refers to measures, processes and procedures to manage the different hazards that may arise during the project life cycle, including, but not limited to, physical, chemical, biological, psychological and radiation hazards.

Independent Verified Auditing and Reporting Plans describe the different audit and reporting activities to undertake during the project life cycle. Independent audits and reports refer to third-party verification systems that examine data, statements, records, operations and performances, with the aim of comparing the baseline with actuals.

Project Life Cycle Assessment (PLA) is also known as life cycle analysis, eco-balance, or cradle-to-grave analysis. PLA is a technique used to evaluate the different environmental impacts associated with all the phases of a product's life cycle, starting from raw material extraction to the final stages of disposal or recycling.

Regulatory Compliance (approvals, licenses, and permits) is a verification process of approvals, licenses and permits to operate.

Safety Management Plan (which includes safety training, reporting, and prevention of incidents) is a formal document that highlights the processes and procedures to manage the area of safety in the project. The plan includes, but is not limited to, safety training programs, reporting, performance measurement, goal setting and incidents prevention.

Social Impact Assessment (SoIA) is a methodological review of the intended and unintended social impacts, effects and consequences - both negative and positive - of project or development interventions. 
Solid Waste Management Plan is developed with the aim of identifying an effective and efficient manner to collect, transport, process/dispose, manage and monitor solid waste material.

Sustainable Public Procurement Strategies highlight the acquisition of material and equipment, with the aim of supporting the green and sustainable goals of the project. For example, this may include material that comes from certified sustainable production activities (e.g., wood) or equipment with lower rates of GHG emissions or energy consumption.

Strategic Environmental Assessment ( $S E A$ ) serves as a tool in the decision support process. The main objective of the assessment is to ensure that informed decisions regarding sustainable development are made by effectively incorporating environmental aspects into policies, plans, and programmes.

Water Management Plan identifies the different strategies for water consumption and usage. The plan must effectively set water conservation goals and identify water conservation opportunities.

\section{C.2. SITE AND SOIL RESOURCE EXCELLENCE - SSRE}

Biological Monitoring Studies and Reports are used to describe the existence of biological impairments. The health of biological systems is identified through biological monitoring, in which a description of the consequences of human activities on the systems are presented, and a distinction is made between naturally occurring variations and human-induced changes.

Deforestation indicates the permanent removal or destruction of a forest or area of trees in order to make the land available for other uses, which implies the land is thereafter converted to a non-forest use.

Mining Effluents: Monitoring, Control, and Reduction refers to measures undertaken to minimise impacts, control emissions and improve the overall performance of the operations related to the emanation of certain substances that includes, but is not limited to, arsenic, copper, cyanide, lead, nickel, zinc, total suspended solids (TSS), and radium. Monitoring, control, and reduction activities also refer to levels of $\mathrm{pH}$.

Overburden Management indicates the different steps that are taken toward dealing with the material that lies above the mining area of interest. In surface mining operations of oil sands, the overburden may include rock, soil and ecosystems. Overburden is also known as waste or spoil. 
Percentage of Resource Extracted Relative to the Total Amount of the Permitted Reserves of that Resource identifies the operational ratio of a determined area in volume (quantity extracted) and time (rate in time).

Proportion of Non-previously developed Land Used measures the length of a new developed area (i.e., mining area) in reference to the non-previously developed land area, but with a high probability of being developed in a determined region, area, or legal jurisdiction.

Proportion of Protected Land Used is the ratio of area under development in relation to the protected land in a determined region, area, or legal jurisdiction.

Re-used Excavation Material proportionally quantifies the percentage of excavated material that is being re-used (e.g., overburden) or effectively extracted to meet the end goals of the operations (e.g., the ratio of oil per ton of extracted oil sand).

Structures to Prevent Erosion and Soil Runoff: Implementation and Monitoring examines all the construction, control, and monitoring of structures designed to prevent erosion and soil runoff in the mining area and its vicinities.

Total Waste Extracted (non-saleable, including overburden) measures the material extracted from the mining area, which includes material that is not being re-used through the overburden management plans, as well as strategies and the waste material (non-saleable or recyclable) extracted during the operational phase of the mine.

Tree Harvest Management identifies the strategies for efficiently and effectively harvesting trees in the area of the operations. It also refers to the total area (i.e., number) of trees harvested in reference to the total area of the mining operations.

\section{C.3. WATER RESOURCE EXCELLENCE - WRE}

Acid Drainage: Monitoring, Control, and Reduction indicates strategies to manage the acid drainage that results from mining activities. Although acid drainage is usually referred to as the outflow of acid water from metal or coal mines, the surface mining operations for oil sands projects must monitor the existence of acid drainage, and, if required, put in place control and reduction strategies. Acid drainage is also referred to as acid mine drainage, acid and metalliferous drainage (AMD), or acid rock drainage (ARD).

Aquatic Life: Protection and Monitoring refers to measures that must be put in place to preserve the aquatic ecosystems in the area of operations. 
Construction of Water Management Systems and Structures entails the construction of different infrastructure systems to control bodies of water resulting from mining operations. Additionally, rain water and other external water effluents are to be considered. The structures for water management after processing the oil sands are to be included as well; however, the indicator does not refer to water management during the processing of the oil sands.

Control of Formation Dewatering measures the procedures in place for dewatering and deposition strategies applicable for each mining site. Usually, each site needs to be considered separately when applying the best dewatering technology. Dewatering technologies include thickening, in-line flocculation, centrifuge, and co-mingling, among others, and deposition strategies include thick lift, thin lift, deposition cells, single-point discharge, and multiple-spigot discharge, among others.

Ground Water Resources: Protection and Monitoring refers to existing and naturally formed water resources, and the different strategies that must be put in place to protect the natural state. The management of ground water resources must include a permanent monitoring system.

Mining Effluents: Monitoring, Control, and Reduction refers to measures undertaken to minimise impacts, control emissions, and improve the overall performance of the operations in relation to the emanation of certain substances into any body of water. The different substances include, but are not limited to, arsenic, copper, cyanide, lead, nickel, zinc, total suspended solids (TSS) and radium. Monitoring, control, and reduction activities also refer to levels of $\mathrm{pH}$.

Muskeg Drainage: Monitoring, Control, and Reduction indicates the different measures used to prevent and minimise the presence of muskeg drainage in the mining areas of the project.

Seepage Prevention (from ponds, pits, and landfills) refers to measures taken to prevent the seepage or leakage of fluids from ponds, pits and landfills. The different measures are meant to prevent any source of contamination from bodies of water.

Usage of Recycled Water measures the percentage of water re-used in the mining process, with the aim of minimising the water intake from naturally formed bodies of water such as rivers or lakes.

Wastewater Management refers to the different strategies to manage the water used in the mining process. In this indicator, not only is wastewater from sanitary sewage and stormwater sources included, but so too is contaminated water resulting from the processing of the mining material.

Water Supply and Consumption includes the quantities of water consumed during the mining process and other activities (e.g. human consumption). 


\section{C.4. ATMOSPHERE AND AIR RESOURCE EXCELLENCE - AARE}

Dust Control indicates the measures taken to minimise the number of particles in the atmosphere originating from different sources, including soil dust lifted by either weather or pollution.

Fugitive Emissions: Monitoring, Control, and Reduction refers to the management of the emission of gases or vapours from pressurised equipment during the surface mining process. The fugitive emissions usually refer to leaks and other unintended or irregular releases of gases.

GHGs: Monitoring, Control, and Reduction refers to measures undertaken to minimise impacts, control emissions and improve the overall performance of the operations related to the emanation of certain substances into the air. The different substances include, but are not limited to, sulphur dioxide $\left(\mathrm{SO}_{2}\right)$, ozone $\left(\mathrm{O}_{3}\right)$, nitrogen dioxide $\left(\mathrm{NO}_{2}\right)$, particulate matter (PM2.5), carbon monoxide $(\mathrm{CO})$, oxides of nitrogen $\left(\mathrm{NO}_{x}\right)$, volatile organic compounds (VOCs), and hydrogen sulphide $\left(\mathrm{H}_{2} \mathrm{~S}\right)$.

Noise and Vibration Management refers to management strategies to monitor, control and reduce the noise and vibrations from transportation and processing equipment during the surface mining process.

\section{C.5. NATURAL AND ARTIFICIAL LIGHTING EXCELLENCE - NALE}

Luminosity: Control and Regulatory Compliance includes any luminosity required by law to perform mining activities in a safe manner. In the event that any luminosity activity is not mandatory by law, a minimum level of luminosity is required to perform any activity in the surface mining area.

\section{C.6. ENERGY RESOURCE EXCELLENCE - ERE}

Consumption of Secondary Energy (electricity and heat) indicates the levels of secondary energy consumption during the operations related to surface mining activities. Secondary energy refers to electricity and heat. Secondary energy is also defined as any form of energy generated by the conversion of primary energies; for example, electricity is transformed from primary sources such as coal, raw oil, fuel oil, natural gas, wind, sun, streaming water, nuclear power, 
gasoline, etc. Secondary energy also refers to refined fuels such as gasoline or synthetic fuels such as hydrogen fuels.

Consumption of Primary Energy (natural gas, LPG (Liquefied petroleum gas), petrol, and other fuels) indicates the levels of primary energy consumption during the operations related to surface mining activities. Primary energy refers to energy found in nature that has not been exposed to any transformation process. Some examples of primary energy are crude oil, hard coal, NGLs (natural gas liquids), natural gas, nuclear, waste, biomass, wind, hydro, and tides, among others.

Internal Production of Energy Consumed (renewable energy use) measures the level of energy produced internally for the project to become self-sufficient. It implies the minimum consumption of energy from external sources.

\section{C.7. RESOURCE AND MATERIALS EXCELLENCE - RME}

Distance (proximity) of Materials Suppliers is designed with the aim of minimising the transportation of materials for the mining process from far distances. Local and nearby businesses should be the first providers of the mining developers and operators.

Hazardous Materials Management, Storage, and Disposal refers to the implementation of strategies for the management, storage and disposal of those materials that present a risk to health or the environment. Hazardous materials can be radioactive, explosive, gaseous, flammable, leachable, corrosive, combustible or toxic.

Improvement in Machine Application Efficiency measures the level of optimisation (i.e. comparison analysis between design and operation indicators) in the use of the machines and equipment utilised during the mining process. It also includes transportation and mining equipment such as shovels and trucks.

Machines Material Re-use indicates the re-utilisation of machinery, with the aim of minimising the purchase of brand new parts to fix or for maintenance purposes of machines or equipment currently in use to maintain their operability and extend their usable lifespan.

Solid Waste Management (non-renewable resources): Reduction, Reuse, and Recycling refers not only to solid material but also liquid, gaseous and radioactive waste. A set of management strategies for the collection, transport, processing or disposal, management, and monitoring of waste material as a result of human activity during the different mining activities.

Usage of Chemical Substances indicates the level of use of toxic substances during the process. The aim is to control and minimise the use of substances that 
present potential risks to the environment and humans. Contaminants can potentially affect air, soil, and water resources and ecosystems in the areas surrounding a mining project.

\section{C.8. INNOVATION IN DESIGN AND OPERATIONS EXCELLENCE - IDOE}

Clean Technology Innovations: Testing and Implementation of New Technologies refers to the effective and efficient implementation of new technology, with the aim of improving performance and minimising the impacts generated due to oil sands operations. The level of success of certain technology is measured using parameters such as reduction of emissions of GHG and energy consumption. Investment in Innovation measures the levels of investment of developing organisations toward technology innovation, with the aim of improving performance and minimising the impacts generated due to oil sands operations.

\section{C.9. INFRASTRUCTURE AND BUILDINGS EXCELLENCE - IBE}

Affected Species: Animal and Vegetal measures the number of species affected and the level of the impact on each. The potential impacts on each species must be evaluated before starting mining operations; thereafter, the impacts must be monitored, controlled and reduced by implementing the appropriate measures. Area of Habitat Created/Destroyed (i.e., area disturbed by oil sands development) indicates the percentages of (1) the area created, with the aim of compensating for the impacts resulting from mining operations; and (2) the area destroyed or disturbed by oil sands development.

Biodiversity and Habitat (includes biological studies and reports): Monitoring and Protection evaluates the management strategies put in place to monitor and protect the biodiversity and habitat of the area of the mining operations.

Communication and Transportation Facilities evaluates the effectiveness of the road and transportation system in the area of the mining project, and the impacts on fuel consumption and travel times.

Ecological Footprint assesses the total amount of land and resources used. The assessment includes the carbon footprint of the mining operations. In other terms, the ecological footprint evaluates how much biocapacity there is in contrast with how much biocapacity people use. 
Mining Location Within or Proximal to Water Bodies is evaluated with the aim of reducing the mining operations within a minimal distance of bodies of water. Minimising impacts on any bodies of water (including ground water) should be a priority of mining projects developers; therefore, the location of bodies of water must be taken into consideration when evaluating the location of surface mining projects.

Proximity of Mining Operations to Mining Material Processing and Tailing Ponds is designed with the aim of minimising distances between extraction areas and material processing facilities and tailing ponds. Intrinsically, this indicator evaluates the effectiveness of the road and transportation systems, but with a focus on the transportation of raw and processed mining material.

Reduction of Land Area Used for Tailings Ponds Operations indicates improvements made by mining projects developers toward reducing the use of areas of land for tailings pond operations. Reducing land use for tailings pond operations probably represents, among other things, the reduction of water use and the implementation of newer technology or methods in the oil sands processing to better the current rates of water consumption.

Tailings Ponds Location and Impacts Study evaluates the location of tailings ponds in reference to other locations in which the impacts might be potentially lower. Implications of locating the tailings ponds in other areas (farther) must be evaluated. The assessment includes, but is not limited to, impacts on energy consumption, travel distances and productivity.

Total Area of Permitted Developments examines the rates at which the development is occurring; the percentage does not refer to projects under construction or in the operation stages, but instead, to projects in the permitting and approval stage. The total area of permitted development must be compared against the total area of potential development.

Total Land Area Newly Opened for Extraction Activities (including area for overburden storage and tailings) refers to the percentage of areas used for new developments compared against the total area of potential development; it includes mining operations, overburden and tailings ponds, among others.

Transportation Distance of Customers, Business Travel, Workforce, and Community for Fly-In and Fly-Out Operations is designed with the aim of reducing travel distances; among other factors considered in this indicator are the encouragement of reduction of fuel consumption and development of local communities.

Vegetation: Monitoring and Control refers to management strategies to monitor and control the different impacts on vegetation in the area of the mining operations. 
Wildlife: Monitoring and Protection refers to management strategies to monitor and control the different impacts on wildlife in the area of the mining operations.

\section{C.10. EDUCATION, RESEARCH, AND COMMUNITY EXCELLENCE - ERCE}

Community and Stakeholder Consultation and Involvement indicates the management strategies for the effective and efficient involvement of the different stakeholders in each phase of the project life cycle. A process for the identification and classification of stakeholders must occur before the subsequent engagement phase takes place.

Community Awareness Programs measures the different awareness programs implemented during the project life cycle, the rate of participation, and the programs' effectiveness. Among others, the set of programs includes aspects such as safety and environmental, social, health and economic impacts, among others. The programs are directed toward community members impacted by the surface mining projects development.

Contribution to Economic and Institutional Development of Communities demonstrates the degree to which surface mining developers are involved with the economic and institutional development of the communities nearby and affected by the project's operations.

Contribution to GDP assesses the level of impact (or percentage of contribution) that a determined surface mining project may have on the gross domestic product (GDP).

Contribution to Social Development of Communities demonstrates the degree to which surface mining developers are involved with the social development of the communities nearby and affected by the project's operations.

Employment, Unemployment, and Underemployment Rates indicates the percentage of these three measures in the areas nearby and affected by the surface mining project's operations; the indicator is designed with the aim of incentivising high rates of employment and lower rates of unemployment and underemployment in these regions.

Employee Turnover refers to the rate at which employers (i.e. surface mining projects developers) gain and lose employees, or the ratio of the number of employees that had to be replaced in a given period of time to the average number of employees; therefore, the objective of the employers is to have lower turnover rates in their projects. 
Environmental Liabilities measures the type of insurance and the quality of its coverage acquired by surface mining projects developers toward protecting (i.e. preventing and remediating) the environment in the event of any damage occurring because of their operations.

Ethical Investment is also known as socially responsible investing (SRI). It refers to those investment strategies that consider both financial return and social good. The indicator measures the percentage of the total investments made by the surface mining projects developers that can be classified under the ethical investment status.

Expenditure on Environmental Protection refers to the rate of investment made toward environmental causes. For example, this may include investments made into training and prevention programs on environmental protection that are directed toward employees and communities nearby and affected by the surface mining project's operations.

Expenditure on Health and Safety refers to the rate of investment made toward health and safety causes. For example, this may include investments made into training and prevention programs on health and safety that are directed toward employees and communities nearby and affected by the surface mining project's operations.

Fatalities at Work indicates the number of lives lost in the workplace (i.e. surface mining area) in a given period of time. The main objective of the indicator is to provide motivation for the implementation of high safety standards and procedures in order to have zero fatalities at work, and no time lost due to injuries and incidents.

Female-to-Male Wage Ratio provides motivation for gender equality. The ratio measures the difference in income between genders that perform the same job duties and have similar responsibilities in the workplace.

Health Care Management/First Aid Facilities refers to management strategies that guarantee proper health care coverage for employees. The indicator also reflects the adequate service and location of first aid facilities in the workplace. For example, a minimum number of health care professionals must be available in the work facilities at all time (ratio of employees to health care professionals).

Health, Pension, and Other Benefits and Redundancy Packages Provided to Employees as Percentage of Total Employment Cost measures the investment made by the organisations (i.e. surface mining projects developers) for each employee in areas such as health, pension, and shares, among other benefits.

Housing Development for Local Communities refers to the degree of involvement of the developing companies in the housing development of communities nearby and affected by the surface mining projects development. 
Housing Provision for Workforce indicates the percentage of that workforce that has been provided with housing nearby or in the project's facilities.

Inflation Rate assesses the level - if any - of impact that a determined surface mining project may have on the inflation rate.

Internal Return Ratio is also known as internal rate of return (IRR), economic rate of return (ERR), discounted cash flow rate of return (DCFROR), or rate of return (ROR). The indicator measures the profitability of investments. A surface mining project with a higher internal rate of return is more desirable for the developers to undertake the project.

Investment in Employee Training and Education measures the level of investments that an organisation has made toward the career development of its employees.

Investment in Research indicates the percentage of resources invested in research with the aim of improving performance toward minimising social, economic, health and environmental impacts as a result of the surface mining operations.

Lost-Time Injuries measures the length of time lost due to injuries in the workplace. The measurement is an indicator of the effectiveness of the safety programs put in place during the operations of the surface mining projects.

Lost-Time Injuries Frequency is designed to indicate the number of injuries with lost-time in the workplace, and the frequency of their occurrence.

Net Employment Creation measures the number of new employees in a surface mining company in a determined period of time. The indicator must take into consideration the number of employees leaving the organisation indifferently of the motive for the termination of the employment.

Net Migration Rate to Project Areas measures the levels of people moving into the areas near the project. The indicator must specifically measure those individuals migrating because of a determined project. The migration rate must count only those individuals directly employed by the project, and differentiate between those migrating with the aim of finding employment.

Number of Direct and Indirect Employees determines the employment created in a specific period of time. Direct employees are those permanently employed by the surface mining company, while indirect employment refers to when businesses that supply or produce goods and services generate employment, or when the surface mining company contracts some work to an individual.

Number of Local Contractors Relative to the Total Number of Contractors measures the number of local contractors hired by the surface mining company during the project's operations. The indicator encourages the utilisation of local 
business instead of contracting the services from contractors outside the region or area of operations.

Number of Local Suppliers Relative to the Total Number of Suppliers measures the number of local suppliers utilised by the surface mining company with the aim of providing their goods and services during the project's operations. The indicator encourages the utilisation of local suppliers instead of importing goods and services from suppliers outside the region or area of operations.

On-going Health Monitoring (workers and local communities) measures the different management strategies and their effectiveness in monitoring the health of workers and local communities nearby and impacted by the operations of the surface mining project.

Participation in Regional Co-operative Efforts indicates the level of involvement of the surface mining company in regional co-operative efforts toward the mitigation of social, economic and environmental impacts, not only in the project area, but also in the region in which the project is located.

Payback Period measures the length of time required for the return or repayment of the total amount of the original investment. This economic indicator is an important factor in determining whether the investors will undertake the project or not. Investors typically do not proceed with developments with long payback periods.

Percentage of Employees Sourced from Local Communities Relative to the Total Number of Employees measures the number (percentage) of employees in the surface mining project hired from nearby or local communities in comparison with the total number of employees in the project. The indicator does not include employees who have migrated with the aim of working on the surface mining project.

Percentage of Employees that are Stakeholders in the Company indicates the number of employees that own any amount of share of stocks in the surface mining company. The indicators must take into consideration those employees that choose to not own any shares even though the developing company has offered them to the employee.

Percentage of Ethnic Minorities Employed Relative to the Total Number of Employees refers to the number of employees from visible minorities in relation to the total number of employees in a determined surface mining project.

Percentage of Hours of Training measures the number of hours of training employees have received from their employers in a determined period of time. The training may include areas such as safety, environmental, social, and economic impacts awareness, and technical training to improve employees' work performance and build upon career development. 
Poverty Alleviation of Affected Areas assesses the contribution of surface mining developers toward the alleviation of poverty in nearby or local communities affected by the project's development.

Project's Acceptability indicates the level of acceptance the surface mining project has among nearby communities and those directly impacted by the development.

Ratio of Lowest Wage to National Legal Minimum identifies the lower wage paid among the different jobs in the surface mining project, and then compares it to the national legal minimum wage that applies in the region (province) in which the surface mining project is located.

Return of Investment considers the profits in relation to the capital invested. The indicator is used to measure the efficiency of the investment (i.e. the surface mining project), or, in the case of having various investment options, the indicator compares the efficiency among them.

Total Number of Health and Safety Complaints from Local Communities monitors and measures the number of complaints from the residents of nearby and local communities impacted by the surface mining projects. Issues of health and safety are among the areas to be included in the monitoring system.

Wealth Distribution measures the gap between the different social classes (i.e. groups in a society) in the regions or areas nearby and impacted by the surface mining project development.

Women/men Employment Ratio encourages gender equality by comparing the number of women and men employed by the surface mining company.

Workforce Awareness and Training Programs (safety, and environmental, social, economic, and health impacts) measures the different awareness and training programs implemented during the project life cycle, the rate of participation, and the effectiveness of those programs. Among others, the set of programs includes aspects such as safety and environmental, social, health, and economic impacts, among others. The programs are directed towards projects' workforce participants.

Work Satisfaction indicates the level of conformity of employees in their current job and with their employers. The indicator includes the areas of affective and cognitive job satisfaction.

\section{REFERENCE}

Poveda, C., \& Lipsett, M. (2014). Surface mining operations in oil sands: Establishing sustainable development indicators (SDIS). Southampton: WIT Press. 